\title{
PERCEPÇÕES DE JUSTIÇA DOS PROFESSORES DO ENSINO SUPERIOR \\ Um estudo confirmatório
}

\author{
Arménio Rego
}

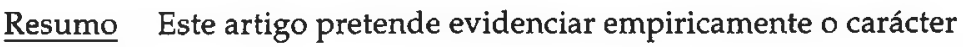
multidimensional das percepções de justiça dos professores do ensino superior. A amostra é constituída por 206 docentes de seis instituições. Os resultados convergem com os anteriormente apresentados por Rego (2000e): a) os professores distinguem cinco facetas da justiça: distributiva das recompensas, distributiva das tarefas, procedimental, interpessoal e informacional; b) este pentamodelo ajusta-se melhor aos dados do que os modelos alternativos de dois, três ou quatro factores; c) o instrumento de medição parece satisfazer requisitos fundamentais de parcimónia, consistência interna e clareza da estrutura dimensional.'
\end{abstract}

Palavras-chave Percepções de justiça, professores do ensino superior, análise factorial confirmatória.

\section{Introdução}

A multidimensionalidade das percepções de justiça

No seio das abordagens de justiça, podem ser divisadas duas grandes orientações. A primeira é de natureza prescritiva, propondo modos de se alcançar um estado objectivo de justiça. Os seus expoentes são, porventura, Aristóteles (Ross, 1959; Morgan, 1992), na antiguidade, e Rawls (1971), na era contemporânea. A premissa subjacente é a de que existem determinadas regras e princípios que, se implementadas, garantem um estado justo. A segunda orientação é de teor descritivo, preocupando-se em estudar as percepções de justiça e o modo como as pessoas a elas reagem. A lógica subjacente é, por conseguinte, subjectiva.

Um dos domínios em que a orientação subjectiva/descritiva tem sido mais profícua é o das organizações (Cropanzano \& Greenberg, 1997; Greenberg \& Lind, 2000). Uma revisão atenta da literatura permite reconhecer uma grande diversidade de variáveis atitudinais e comportamentais que as percepções de justiça organizacional permitem explicar. A título ilustrativo citam-se a implicação organizacional, a confiança, a harmonia social, as intenções de permanecer na

Arménio Rego, Universidade de Aveiro. 
organização, o absentismo e o turnover, os comportamentos de cidadania, os comportamentos retaliatórios, a satisfação e o desempenho individual e/ou organizacional (Greenberg, 1990; Cropanzano \& Greenberg, 1997; Rego, 1999, 2000a; Greenberg \& Lind, 2000).

Para esta riqueza empírica contribuiu, em considerável medida, a capacidade dos investigadores para divisarem a multidimensionalidade do construto. Uma grande parte da literatura distingue três dimensões (Greenberg, 1990, 1996; Cropanzano \& Greenberg, 1997; Rego, 2000a; Greenberg \& Lind, 2000):

a) a justiça distributiva (Adams, 1965) foi a que primeiramente suscitou a atenção dos cientistas organizacionais. Focaliza-se no conteúdo, isto é, na justiça dos fins alcançados ou obtidos (e.g., salários, notações de desempenho, sanções disciplinares, promoções, aceitação/rejeição de candidatos, resultados dos testes de detecção de consumo de droga, fatia orçamental atribuída às unidades organizacionais subsidiárias, lucros distribuídos pelos trabalhadores);

b) a justiça procedimental (Thibault \& Walker, 1975, 1978; Lind \& Tyler, 1988) radica no processo, ou seja, na justiça dos meios usados para alcançar tais fins. Concerne, por exemplo, aos procedimentos usados nos acréscimos salariais, processos disciplinares, sistemas de avaliação de desempenho, processos de recrutamento e selecção;

c) a justiça interaccional (Bies \& Moag, 1986; Greenberg \& McCarty, 1990; Tyler \& Bies, 1990; Greenberg, 1993b) reflecte a qualidade da interacção com os decisores (e.g., o decisor age com dignidade e respeito? oferece justificações às pessoas afectadas pelas decisões?).

Pode ilustrar-se o triângulo dimensional com um incremento salarial: o incremento propriamente dito (justiça distributiva), o processo que o determina (procedimental) e o modo como o superior o transmite, explica e justifica ao colaborador (interaccional). Um indivíduo pode considerar que um incremento nulo é justo, que os critérios e processos usados para tal decisão são justos, mas revelar percepções de baixa justiça (interaccional) devido à rudeza com que o superior o aborda e lhe explica a desagradável decisão. Genericamente, pode aduzir-se que as percepções de justiça numa das dimensões podem coexistir com as percepções de injustiça noutras vertentes, e vice-versa.

A distinção entre as facetas distributiva e procedimental é claramente demonstrada por numerosos estudos sugerindo que os seus efeitos são distintos. Uma das teses mais acolhidas pelas investigações é a dos efeitos diferenciais, e propõe que a vertente procedimental está associada com as avaliações do sistema organizacional (reflectidas em variáveis como a lealdade à organização, a implicação organizacional e a confiança na gestão), enquanto a distributiva se associa preferencialmente com a satisfação com os resultados específicos em questão ou os resultados de determinada decisão (Lind \& Tyler, 1988; Folger \& Konovsky, 1989; Greenberg, 1990; Kim \& Mauborgne, 1991, 1996; McFarlin \& Sweeney, 1992; 
Sweeney \& McFarlin, 1993). Este modelo tem beneficiado de algumas hipoleses complementares, que podem ser assim enunciadas (Conlon, 1993; Lowe \& Vodanovich, 1995):

a) a justiça distributiva explica as reaç̧oes dos individuos no curto prazo, isto é, logo que os resultados são conhecidos (especialmente se forem negativos). Diferentemente, a justiça procedimental explica mais significativamente as reaç̧̋es no longo prazo;

b) a justiça distributiva detém maior poder explicativo das reaç̧óes dos individuos em situaçōes de pouca familiaridade com os procedimentos, ou quando estes desconhecem a utilidade e propriedade dos procedimentos usados pela e na organizaço. Em tais casos (e.g., processo de recrutamento/seleç̧ão de curta duraçăo), os resultados adquirem maior saliencia do que os procedimentos. Consequentemente, os individuos reagem em conformidade com eles, ou tomam-nos como indicadores dos procedimentos utilizados.

A distinçăo entre as facetas procedimental e interaccional năo tem recebido, entre os investigadores, acolhimento idéntico ao acabado de expor. Na verdade, embora a importáncia do construto da justiça interaccional seja relativamente consensual, ocorrem divergências entre os que advogam ser ela uma componente da justiça procedimental (a par dos aspectos estruturais) e os que propugnam pela sua autonomia. Um dos argumentos favoráveis à autonomizaçãoé o da necessidade de distinguir os procedimentos da sua implementaçāo (Bies \& Moag 1986). A lógica tripartida é a seguinte: os procedimentos organizacionais geram interacç̋̋es sociais, donde emergem resultados. Pode ilustrar-se o triángulo com o exemplo de uma sançăo disciplinar: a sançăo propriamente dita (justiça distributiva), o processo que a determina (procedimental) e o modo como o superior a transmite, explica justifica ao colaborador (interaccional). Um individuo pode considerar que a sançăo e o processo sảo justos, mas revelar percepç̄es de baixa justiça (interaccional) devido à ausencia de tratamento respeitador e digno por parte do superior.

Sucede que esta distinção emerge com menos limpidez quando se pensa na eventualidade de o tratamento interpessoal recebido pelo individuo poder influenciar (positiva ou negativamente) as suas percepçōes acerca dos resultados recebidos e dos procedimentos que os originaram. Mais concretamente, é plausivel que o tratamento interpessoal recebido por um individuo sancionado influencie (positiva ou negativamente) as suas percepçðes acerca da justiça da sanção disciplinar que lhe foi aplicada e do processo que a suscitou. Talvez por isso, a versāo autonomizadora tem colidido com os contributos de alguma evidéncia empírica. Com efeito, a inexistência de componentes distintas em estruturas factoriais, a relaçāo forte entre os aspectos estruturais e interpessoais, e a similitude de consequéncias de ambas as facetas têm convergido para que conceituados investigadores se mostrem hoje inclinados para a näo-autonomizaçăo (Cropanzano \& Greenberg, 1997).

Mas uma das demonstrações mais cabais de que o campo de estudo ainda dá 
diferenciado pode permitir testar se são ou não independentes os efeitos de cada vertente sobre as reacçōes dos indivíduos. Os trabalhos de Greenberg são elucidativos. Em pesquisas atinentes aos efeitos de uma reduçăo remuneratória, uma proibiçăo de fumar e um despedimento (vd. síntese em Greenberg, 1993b: 87-95), um padrão similar de resultados foi obtido:

a) as reacçðes negativas foram menores na condiçăo de justiça informacional e interpessoal elevada, e maiores quando ambos os factores eram elevados. Mais precisamente, cada tipo de justiça contribuiu aditivamente para a reduçð̄o das reacçỏes negativas;

b) a justiça social mitigou as potenciais reaç̧oes negativas dos individuos a resultados adversos ou injustos. Ou seja, "a prestaçăo de explicaçðes rigorosas acerca dos procedimentos, acompanhadas de demonstraçðes de sensibilidade relativamente a situaçð̋es desagradáveis sofridas pelos empregados, reduz efectivamente... os niveis de furto, promove a aceitação de uma proibição de fumar por aqueles que mais sâo negativamente afeclados, e decresce o sentimento negativo relativamente à empresa que despede" (Greenberg, 1993b, p. 95).

Sensíveis a pertinència da distinçāo, Greenberg \& Lind (2000) afirmaram recentemente: "individual e conjuntamente, cada um destes factores contribui para a crença das pessoas de que săo tratadas com justiça, e fomenta a aceitaçăo dos resultados distribuídos" (p. 80). A recente evidéncia empírica obtida por Rego (2000d) aponta igualmente para as vantagens de se proceder ao tratamento separado: quando introduziu as duas vertentes nas regressóes, apenas a interpessoal/social denotou poder preditivo de várias dimensōes de cidadania. Em suma: parece que o discernimento das duas facetas pode incrementar o poder explicativo das reaç̧óes dos individuos, seja porque cada vertente explica diferentes reaç̧ðes, seja porque adiciona poder explicativo ao poder preditivo da outra vertente.

\section{Percepçoes de justiça de professores do ensino superior}

Do exposto se conclui que existe um manancial precioso de pesquisas no dominio da psicologia industrial/organizacional. Todavia, sto muito escassas as que se debruçam sobre as percep̧ōes de justiça dos docentes do ensino superior (Rego. 2000 e, 2000 $)$. E embora seja presumivel que as reacçðes atitudinais e comportamentais destes docentes obedeçam aos padròes jú encontrados na psicologia industrial/organizacional, há todo o interesse em que seja realizado trabalho empírico que permita testar tal hipótese. Para tal, é crucial dispor de instrumentos de mediçăo apropriados.

A literatura em psicologia industrial/organizacional é prołusa em instrumentos psicometricamente válidos, pelo que se poderia perfilhar um de entre eles para a prossecuçăo de tal trabalho empíico. Mas parece razóvel supor que as 
condições específicas do exercício da actividade docente podem acarretar a necessidade de adoptar instrumentos apropriados ao contexto (Greenberg, 1993a) e de com eles testar a multidimensionalidade do construto. Esta especificidade de condições é reforçada nas instituições públicas de ensino, sendo sobre elas que o presente artigo se debruça.

Em primeiro lugar, parece haver razões para presumir que, contrariamente ao detectado em meios organizacionais "comuns", os professores distinguem duas vertentes de justiça distributiva: distribuição das tarefas e distribuição das recompensas salariais. Regra geral, em meios industriais/organizacionais "comuns", a entidade que distribui as recompensas é a mesma que distribui as tarefas. Tende, aliás, a existir um nexo bastante forte entre uma e outra parte do binómio. Talvez por essa razão, os estudos sobre justiça organizacional tendem a operar apenas com uma dimensão de justiça distributiva. Nos meios docentes do ensino superior, algumas nuances poderão aportar uma lógica algo distinta:

a) a entidade que distribui o trabalho docente (a instituição onde trabalha o professor) não tem correspondente controlo sobre as recompensas: a estrutura salarial está dependente de factores legais, estatutários e políticos que ultrapassam as fronteiras de possibilidade de actuação da instituição empregadora;

b) a distribuição do serviço docente é feita semestre a semestre, ou ano a ano havendo, nalguns casos, bastante fluidez no modo como é desenhada periodicamente. As possíveis flutuações nessa matéria não têm correspondência exacta no plano das remunerações;

c) os professores são impelidos à execução de diversas actividades (docentes ou não), cuja quantidade, modo de exercício e desempenho não têm implicações claras e imediatas no fluxo de remunerações auferidas. Idênticas funções podem estar associadas a diferentes remunerações. Diferentes níveis de desempenho podem coexistir com idênticas remunerações.

Em segundo lugar, a supervisão directa - habitual na maior parte das organizações - não tem correspondência exacta na actividade dos docentes do ensino superior. Designadamente, estes membros organizacionais devem obediência a vários tipos de superiores (nos planos administrativo, científico, pedagógico). A actividade docente é executada com uma dose assinalável de independência - o que torna as interacções superior-subordinado menos frequentes do que as verificáveis noutros tipos de organizações. Esta peculiaridade torna-se mais clara quando se cogita sobre a influência exercida pelo supervisor directo nos processos de avaliação de desempenho, decisões de promoção, incrementos salariais e controlo das actividades dos seus subordinados - processos esses que não têm idêntica configuração na actividade dos professores do ensino superior (pelo menos em instituições públicas).

Em terceiro lugar, é plausível que a relativa independência no exercício da actividade docente possa induzir os professores a uma certa secundarização da 
sensibilidade social recebida dos seus superiores (Greenberg, 1993b; Greenberg \& Lind, 2000) - mas isso nāo impede que reajam ao facto de serem ou năo chamados a participar nas (ou de receberem explicaçoes pelas) decisoles que lhes dizem respeito. Ou seja: parece haver razőes para presumir que os professores distinguem as facetas informacional e social da justiça interaccional, e reagem-lhes diferentemente.

Em quarto lugar, muitos procedimentos (atinentes, por exemplo, à distribuiçăo de funçðes, promoç⿸̄es, mecanismos de recrutamento e selecçăo) adoptados nas instituiçós de ensino superior públicas resultam de imperativos legais e estatutários com origem externa. Diferentemente, os procedimentos adoptados nas organizaçðes em geral săo de origem interna, isto é, provenientes de políticas e práticas da própria organização. Uma das consequências desta situaçăo é a seguinte: enquanto que, nas organizaçðes em geral, as autoridades seguem procedimentos em cuja feitura e modificaçăo elas próprias tendem a participar, as autoridades das instituiçbes públicas de ensino sto impelidas a adoptar procedimentos de origem externa, em cuja feitura nāo participaram, aplicáveis às demais instituiçð̄es do mesmo sector, e cuja alteraçăo está, em grande medida, fora do seu controlo. É provável que daqui decorram consequências no plano das relaçôes entre os docentes e os seus superiores. É plausivel que os docentes distingam mais claramente os actos que eståo sob controlo dos seus superiores e os que năo eståo. Dito de outro modo: pode suceder que os professores distingam mais claramente as facetas procedimental e interaccional da justiça.

Por conseguinte, há razỏes para presumir que o contexto das unstituiçőes de ensino superior é diferente do encontrado noutras organizaçós industriais ou de serviços. Dal podem resultar duas particuliaridades. Primeira: $t_{\text {possivel que os }}$ factores subjacentes as percepçdes de justiça nestes dois tipos de organizaçdes sejam distintos. Segunda: é provável que a estrutura dimensional seja igualmente peculiar.

Importa referir que a pentadimensionalidade atrás insinuada já recebeu alguma confirmaçăo empírica. Com efeito, Rego (2000e) extraiu - numa amostra de 208 docentes de dois universidades e duas instituiçöes politecnicas - quatro factores, explicando $65 \%$ da variância total: justiça interaccional ( 13 itens; alfa: 0,95 ), just $i-$ fa distribution das recompensas (12 itens; 0,95), justica procedimental (8 itens; 0.89) e justiça na disf ribuiçdo das tarefos ( 6 itens; 0,86 ). Nessa mesma investigaçăo, Rego também detectou vantagens em discernir entre as vertentes interpessoal e informacional da justiça interaccional. Na verdade, quando tentou explicar a implicação afectiva dos professores (Allen \& Meyer, 1996, Meyer 1997), constatou que as variâncias explicadas eram superiores se se procedesse à consideraçăo separada dessas duas vertentes. Mais: nesse caso, apenas a justiça informacional denotava poder preditivo significativo. A presente investigaçăo visa, precisamente, testar empiricamente esta pentadimensionalizaçăo. Tentaremos executar várias análises confirmatórias, tendo em vista saber qual dos modelos factoriais sugeridos pela prévia investigaçăo de Rego (2000e) se ajusta mais satisfatoriamente aos dados. 


\section{Método}

A amostra é constituida por 206 professores do ensino superior público, oriundos de tres universidades e tres instituiçőes politénicas, e ocupando diferentes categorias na carreira docente. Atendendo a que foram distribuídas 750 missivas, a taxa de devoluça foi de $27 \%$. Cada inquirido foi convidado a expressar as suas percepçðes de justiça através de um questionário contendo 34 itens seleccionados de entre os 39 remanescentes da análise factorial exploratória levada a cabo por Rego (2000). Para o efeito, foi-lhes solicitado que assinalassem o grau de concordancia com as afirmaçðes consignadas nesses 34 descritores, através de uma escala de seis pontos (1: "discordo completamente"; 6: "concordo completamente"). Este questionário havia sido desenvolvido por Rego ao longo de um processo com várias ctapas:

a) por um lado, o investigador extraiu descritores na literatura (assinalada com asterisco na seç̧ão "referencias");

b) por outro lado, realizou um estudo exploratório no seio do qual procedeu a análise de conteúdo do material semántico produzido por 51 professores do ensino superior (oriundos de trés universidades e uma instituiçāo de ensino politécnico portuguesas). As perguntas formuladas a estes docentes incidiram sobre os aspectos que, no seu entender, eram fontes de injustiça e/ou poderiam contribuir para os incrementos da justiça;

c) $\quad 0 s 72$ itens oriundos das duas fontes foram entảo consignados num questionário que, após depuraçăo gerada pela análise factorial das componentes principais, ficou reduzido aos 39 descritores atrds assinalados.

Na presente pesquisa, para cada uma das cinco dimensóes, foi removido o item que denotava a mais baixa saturação na análise factorial executada por Rego (2000e). $O$ questionário ficou então reduzido aos 34 descritores já citados. Os dados foram submetidos a várias análises factoriais confirmatórias (com o recurso ao LISREL, e com base no método da máxima verosimilhança). Em primeiro lugar, testou-se o tetramodelo emergente da análise factorial executada por Rego (2000). Os índices de ajustamento revelaram-se pouco satisfatórios (e.g., RMSEA: 0,09; GFI: 0,73; AGF1: 0,$69 ; C F 1: 0,85)$, o que năo surpreende se atentarmos na elevada quantidade de descritores consignados no modelo. Foram entảo removidos diversos itens à luz dos índices de modificaçăo e dos residuos estandardizados (Joreskog \& Sorbom, 1993; Byrne, 1998), até se alcançar um modelo cujos índices de ajustamento fossem satisfatórios. Os 17 itens remanescentes estảo expostos no quadro 1. Foram, depois, testados outros quatro modelos:

a) no pentamodelo, consideraram-se os factores informacional, interpessoal, procedimental, distributivo das ta refas e distributivo das recompensas. Para o efeito, os itens interaccionais emergentes em Rego (2000) foram distribu(dos por dois factores (interpessoale informacional), de acordo com o seu teor semántico; 
Quadro 1 Descritores atinentes às vărias dimensōes de justiça

\begin{tabular}{|c|c|}
\hline Categorias & Itens \\
\hline \multicolumn{2}{|l|}{ Justiça interaccional } \\
\hline Justiça interpessoal & $\begin{array}{l}\text { 1. Os meus superiores mostram interesse genuino em serem justos comigo. } \\
\text { 2. Os meus superiores lidam comigo de modo honesto e ético. } \\
\text { 3. Os meus superiores sāo completamente francos e sinceros comigo. }\end{array}$ \\
\hline Justiça informacional & \\
\hline & $\begin{array}{l}\text { 5. Quando tomam decisōes sobre o meu trabalho, os meus superiores dāo-me } \\
\text { explicaçöes com sentido para mim. }\end{array}$ \\
\hline & $\begin{array}{l}\text { 6. Quando tomam decisōes sobre o meu trabalho, os meus superiores } \\
\text { discutem comigo as implicaçōes dessas decisōes. }\end{array}$ \\
\hline Justiça procedimental & $\begin{array}{l}\text { 7. Os critérios usados para as promoçōes sāo justos. } \\
\text { 8. Os procedimentos da minha instituição asseguram que as decisōes são } \\
\text { tomadas sem favorecimentos pessoais. } \\
\text { 9. As decisões são tomadas de modo consistente para todos os professores. }\end{array}$ \\
\hline Distributiva das recompensas & $\begin{array}{l}\text { 10. Tendo em conta a minha experiência, considero que as recompensas que } \\
\text { recebo são justas. } \\
\text { 11. Considerando as minhas responsabilidades, as recompensas que recebo } \\
\text { são justas. } \\
\text { 12. Considerando o stress e pressões da minha actividade profissional, as } \\
\text { recompensas que recebo são justas. } \\
\text { 13. Tendo em conta a correcção com que faço o meu trabalho, considero que } \\
\text { as recompensas que recebo sāo justas. } \\
\text { 14. Considerando o meu esiorço, as recompensas que recebo sāo justas. }\end{array}$ \\
\hline Distributiva das tarefas & $\begin{array}{l}\text { 15. O serviço docente que me tem sido distribuido é justo. } \\
\text { 16. As tarefas que me são atribuidas sāo justas. } \\
\text { 17. Tendo em conta as condiçōes de trabalho que me são facultadas, } \\
\text { considero injustas as tarefas que me sāo exigidas. (i) }\end{array}$ \\
\hline
\end{tabular}

Nota: (j) a pontuação neste item foi invertida.

b) no trimodelo A, trabalhou-se com os factores interaccional (interpessoal + informacional), procedimental e distributivo (tarefas + recompensas);

c) no trimodelo $B$, considerou-se o factor procedimental geral (interpessoal + informacional + procedimental), o distributivo das tarefas e o distributivo das recompensas;

d) no bimodelo, examinou-se o factor procedimental geral (interpessoal + informacional + procedimental) e o factor distributivo global (tarefas + recompensas).

\section{Resultados}

O quadro 2 expōe os resultados deste exame factorial confirmatório aos cinco modelos. Aí se patenteiam os lambdas, os alfas de Cronbach e os índices de ajustamento. Os esquemas factoriais que melhor se ajustam aos dados são os de quatro e cinco 
Quadro 2 Análises factoriais confirmatórias (soluçāo completamente estandardizada)

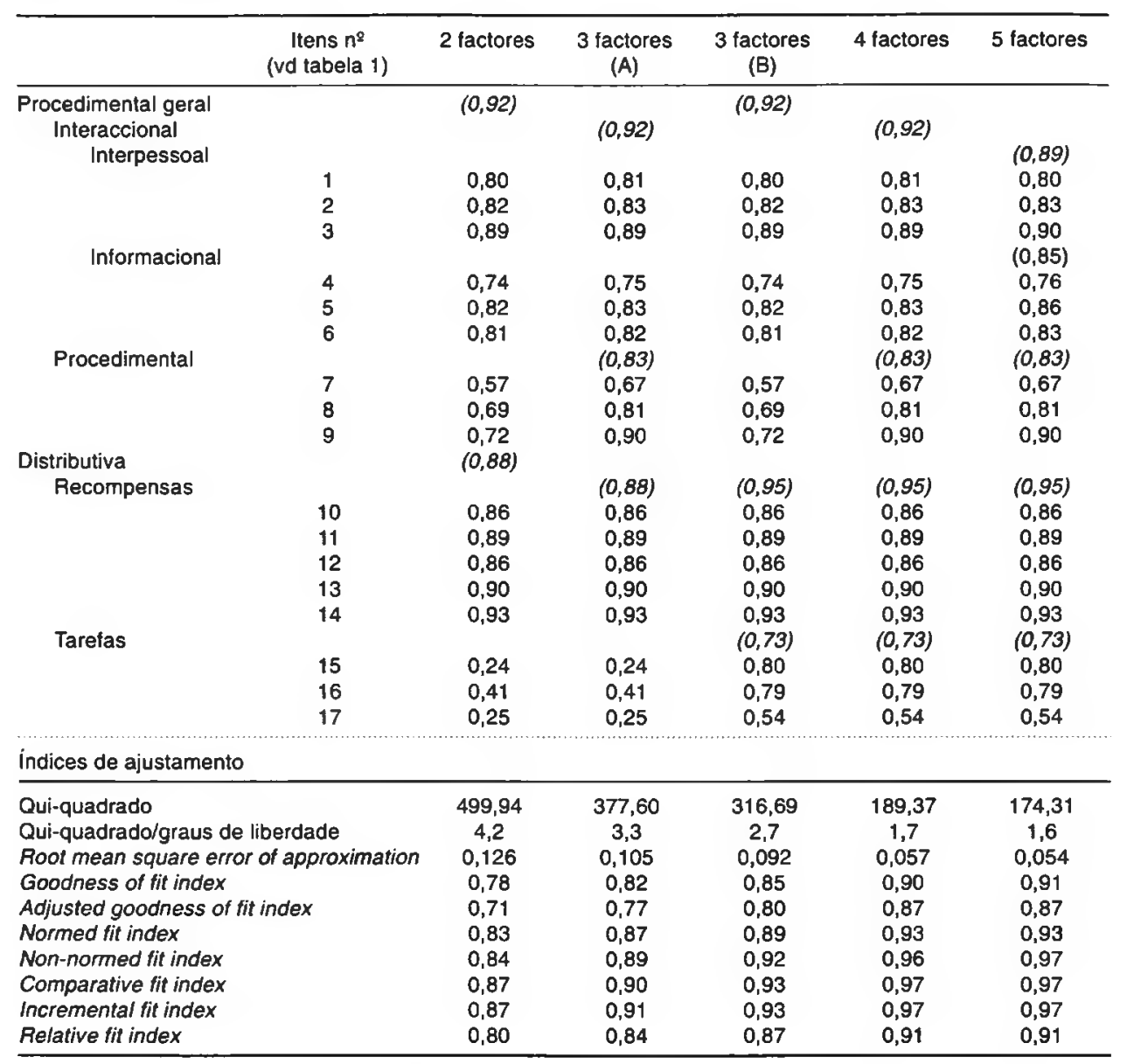

Nota: entre parêntesis os alfas de cronbach.

dimensões, embora o pentamodelo denote uma ligeira vantagem. Frise-se que, nestes dois esquemas factoriais, se cumprem alguns dos principais requisitos para que uma medida seja psicometricamente adequada:

a) os índices de ajustamento são bastante satisfatórios. A título ilustrativo, sublinhe-se que os valores do GFI, NFI, NNFI, CFI, IFI e RFI são superiores a 0,90, tal como recomendado (Joreskog \& Sorbom, 1993; Byrne, 1998).

b) As saturações atinentes aos descritores são sistematicamente superiores a 0,50 , e quase sempre se situam no patamar acima de 0,70 .

c) Os alphas de Cronbach são invariavelmente superiores ao mínimo de 0,70 sugerido por Nunnally (1978). 


\section{Discuss 30 dos resultados e conclusbees}

Os dados empíricos acabados de expor sugerem que há vantagens em considerar as percepçðes dos professores do ensino superior a luz de cinco dimensઠes. Significa isso que apontam no sentido já aventado por Rego (2000). É certo que, da ańlise factorial das componentes principais executada pelo investigador, haviam brotado apenas quatro factores, pois os itens interpessoais e informacionais saturavam um mesmo factor. Mas Rego havia verificado que: a) quando tratava separadamente esses dois grupos de descritores, conseguia mais elevados poderes preditivos da implicaçăo afectiva; b) na regressăo, apenas a vertente interpessoal apresentava um coeficiente significativo. $O$ investigador aventara que esta evidéncia recomendava a execuçăo de análises factoriais confirmatórias, com amostra diferente, tendo em vista comparar a os indices de ajustamento dos modelos tetra e pentafactorial.

Foi precisamente a esse desafio que a presente pesquisa se abalançou. Os resultados confirmam que a hipostese era legítima, e que a consideraçăo separada dos itens interpessaais e informacionais pode ser preferivel à sua junçảo. Deve reconhecer-se que as diferenças entre os indices de ajustamento de ambos os modelos săo muito ténues. Daí deveria resultar a opçăo pelo modelo mais parcimonioso. Mas a evidéncia anterior - mostrando que os poderes preditivos da implicaçăo organizacional gerados pelas facetas interpessoal e informacional sāo distintos - recomenda que se mantenha a partiçăo. Futuras investigaçōes poderăo, todavia, trazer ao campo dados emṕricos adicionais que ajudem a optar por um ou outro modelo.

Importa sublinhar, em qualquer caso, que o instrumento de medida aqui sugerido denota propriedades psicométricas de assinalável valia: é parcimonioso, expressa boas consistencias internas, e revela caracteristicas dimensionais bastante claras. Parece, por conseguinte, representar um ponto de partida para investigaçōes que outros pesquisadores pretendam efectuar. Oxalá surjam estudos visando a explicaçðo de um elenco considerável de atitudes e comportamentos largamente pesquisados em meios industriais/organizacionais. A questăo geral mais pertinente é a de saber se os professores do ensino superior reagirăo às percepçðes de justiça de modo similar ao que tem sido detectado noutros contextos. Será que, designadamente, os professores com percep̧̋́s de justiça mais positivas adoptam maiores indices de comportamentos de cidadania docente (Rego \& Sousa, 2000a, 2000b), denotam maiores níveis de satisfaçăo, se empenham mais na vida organizacional, sentem mais confiança na instituiçăo e suas autoridades, expressam menores nfveis de absentismo? A especificidade multidimensional exposta neste artigo sugere, todavia, questठ́es de investigaçåo mais específicas. Por exemplo:

a) as professores reagirăo distintamente às duas facetas da justiça distributiva? Serd que se empenham menos na sua actividade pedagógica quando se sentem injustiçados na distribuiçāo do serviço docente, mas que essas 
percepções são menos pertinentes para o seu desempenho científico e o empenho em actividades administrativas e de gestão?;

b) em que medida as duas dimensões distributivas interagem na produção de efeitos atitudinais e experimentais? Será que fracos níveis de justiça percepcionada numa dimensão reforçam os fracos níveis na outra dimensão? E será que elevados níveis percepcionados numa faceta mitigam os efeitos de baixos níveis na outra vertente?;

c) qual a faceta interaccional (interpessoal versus informacional) que predomina na explicação das reacções dos professores? Os efeitos serão aditivos ou diferenciais? Será que a justiça interpessoal interfere mais fortemente nos comportamentos de relacionamento com os superiores (e.g., ajuda na revisão de artigos, colaboração em projectos), e que a informacional explica mais claramente a participação na tomada de decisões, a apresentação de sugestōes construtivas, as iniciativas de melhoria?;

d) será que estas duas vertentes interaccionais contribuem de igual modo para mitigar as reacções dos professores às percepções de injustiças distributivas e/ou procedimentais?.

Uma das mais fortes limitações do estudo provém do facto de a amostra ter sido recolhida exclusivamente em instituições públicas. Daqui decorrem, pelo menos aparentemente, dificuldades de aplicação do instrumento de medição às instituições privadas. Estudos posteriores deverão, portanto, proceder a estudos de validação nesse sector de ensino. Importa, no entanto, fazer três referências:

a) genericamente, o conteúdo semântico dos itens parece ser aplicável aos professores dessas instituições. Afigura-se, aliás, ser extensível à generalidade das organizações não académicas, com ligeiras adaptações;

b) embora tenham características distintas (e.g., em termos de recrutamento e selecção, esquemas remuneratórios, sistemas de promoção, avaliação de desempenho), as instituições públicas e privadas partilham características comuns, como sejam a relativa independência da actividade docente e a ténue vigência dos mecanismos de supervisão directa sobre os docentes;

c) recorrendo à linguagem de Mintzberg, pode afirmar-se que a natureza pública/privada não obsta a que ambos os tipos de organizações denotem as características básicas de uma configuração profissional, com todas as peculiaridades daí advenientes em termos de coordenação do trabalho, sistemas de planeamento e controlo, grau de centralização, formalização do comportamento (Mintzberg, 1983; 1998).

Em suma: as percepções de justiça dos professores do ensino superior são um construto multidimensional, parecendo haver razões para trabalhar com cinco dimensões - e não apenas com as três mais frequentemente apontadas na literatura sobre justiça organizacional: distributiva, procedimental e interaccional (Cropanzano \& Greenberg, 1997; Greenberg \& Lind, 2000). Há, porém, necessidade de prosseguir as pesquisas com o fito de esclarecer se não será cientificamente mais 
vantajoso optar por versões mais parcimoniosas - podendo as respostas às questões atrás formuladas contribuir para esse esclarecimento. Importa, igualmente, testar o instrumento aqui proposto em instituições de ensino superior privadas, sob pena de a sua aplicabilidade ficar arredada de um sector de ensino inquestionavelmente relevante no sistema educativo.

\section{Notas}

1 Agradecemos os valiosos comentários dos dois revisores anónimos

\section{Referências}

Adams, J. S. (1965). Inequity in social exchange. In L. Berkowitz (Ed.), Advances in experimental social psychology (vol. 2, pp. 267-299). Nova Iorque: Academic Press.

Alexander, S., \& Ruderman, M. (1987). The role of procedural and distributive justice in organizational behavior. Social Justice Research, 1 (2), 77-198.

Allen, N., \& Meyer, J. P. (1996). Affective, continuance, and normative commitment to the organization: An examination of construct validity. Journal of Vocational Behavior, 49, 252-276.

Aquino, K., Griffeth, R. W., Allen, D. G., \& Hom, P. W. (1997). Integrating justice constructs into the turnover process: A test of a referent cognitions model. Academy of Management Journal, 40 (5), 1208-1227.

Balkin, D. B., \& Gomez-Mejia, Luis R. (1990). Matching compensation and organizational strategies. Strategic Management Journal, 11, 153-169.

Ball, G. A., Trevino, L. K., \& Sims Jr. H. P. (1994). Just and unjust punishment: Influences on subordinate performance and citizenship. Academy of Management Journal, 37, 299-322.

Bies, R. J., \& Moag, J. S. (1986). Interactional justice: Communication criteria of fairness. In R. J. Lewicki, B. H. Sheppard \& M. H. Bazerman (Eds.), Research on negotiation in organizations (vol. 1, pp. 43-55). Greenwich, CT: JAI Press.

Bies, R. J., Martin, C. L., \& Brockner, J. (1993). "Just laid off, but still a good citizen? Only if the process is fair". Employee Responsibilities and Rights Journal, 6 (3), 227-238.

Byrne, B. M. (1998). Structural equation modeling with LISREL, PRELIS, and SIMPLIS. Londres: Lawrence Erlbaum Associates.

Caetano, A., \& Vala, J. (1999). Efeitos da justiça organizacional percebida sobre a satisfação no trabalho e as opções comportamentais. Psicologia, XIII (1-2), 75-84.

Conlon, D. E. (1993). Some tests of the self-interest and group-value models of procedural justice: Evidence from an organizational appeal procedure. Academy of Management Journal, 36 (5), 1109-1124. 
Cropanzano, R., \& Greenberg, J. (1997). Progress in organizational justice: turneling through the maze. In C. L. Cooper \& I. T. Robertson (Eds.), International review of industrial and organizational psychology (vol. 12, pp. 317-372). Chichester: John Wiley \& Sons.

Dittrich, J. E., \& Carrell. M. R. (1979). Organizational equity perceptions, employee job satisfaction and departmental absence and turnover rates. Organizational Behavior and Human Performance, 24, 29-40.

Farh, J., Earley, P. C., \& Lin, S. (1997). Impetus for action: A cultural analysis of justice and organizational citizenship behavior in chinese society. Administrative Science Quarterly, 42, 421-444.

Folger, R., \& Konovsky, M. A. (1989). Effects of procedural and distributive justice on reactions to pay raise decisions. Academy of Management Review, 32 (1), 115-130.

Greenberg, J., \& Lind, E. A. (2000). The pursuit of organizational justice: From conceptualization to implication to application. In C. L. Cooper \& E. A. Locke (Eds.). Industrial and organizational psychology: Linking theory with practice (pp. 72-108). Malden, MA: Blackwell.

Greenberg, J., \& McCarty, C. L. (1990). The interpersonal aspects of procedural justice: A new perspective on pay fairness. Labor Law Journal, 41, 580-586.

Greenberg, J. (1990). Organizational justice: Yesterday, today and tomorrow. Journal of Management, 16, 399-432.

Greenberg, J. (1993a). The intelectual adolescence of organizational justice: You've come a long way, maybe. Social Justice Research, 6 (1), 135-148.

Greenberg, J. (1993b). The social side of fairness: Interpersonal and informational classes of organizational justice. In R. Cropanzano (Ed.), Justice in the workplace: Approaching fairness in human resource management (pp. 79-103). Hillsdale, NJ: Erlbaum.

Greenberg, J. (1996). The quest for justice on the job: Essays and experiments. Thousand Oaks, CA: Sage.

Joreskog, K., \& Sorbom, D. (1993). Lisrel 8: Structural equation modeling with the simplis command language. Scientific Software International.

Kim, W. C., \& Mauborgne, R. A. (1991). Implementing global strategies: The role of procedural justice. Strategic Management Journal, 12, 125-143.

Kim, W. C., \& Mauborgne, R. A. (1996). Procedural justice and managers' in-role and extra-role behavior: the case of the multinational. Management Science, Abril, 499-515.

Kim, W. C., \& Mauborgne, R. A. (1997). Fair process: managing in the knowledge economy. Harvard Business Review, 75 (4), 65-75.

Leventhal, G. S. (1980). What should be done with equity theory? New approaches to the study of fairness in social relationships. In K. S. Gergen, M. S. Greenberg, \& R. H. Willis (Eds.), Social exchange: Advances in theory and research (pp. 27-55). Nova Iorque: Plenum Press.

Lind, E. A., \& Tyler, T. R. (1988). The social psychology of procedural justice. Nova Iorque: Plenum.

Lowe, R. H., \& Vodanovich, S. J. (1995). A field study of distributive and procedural justice as predictors of satisfaction and organizational commitment. Jurnal of Business and Psychology, 10 (1), 99-114. 
Lupfer, M. B., Weeks, K., Doan, K. A., \& Houston, D. A. (2000). Folk conceptions of fairness and fairness. European Journal of Social Psichology, 30, 405-428.

Masterson, S. S.; Lewis, K.; Goldman, B. M., \& Taylor, M. S. (2000). Integrating justice and social exchange: The differing effects of fair procedures and treatment on work relationships. Academy of Management Journal, 43 (4), 738-749.

McFarlin, D. B., \& Sweeney, P. D. (1992). Distributive and procedural justice as predictors of satisfaction with personal and organizational outcomes. Academy of Management Journal, 35 (3), 626-637.

McNeely, B., \& Meglino, B. M. (1994). The role of dispositional and situational antecedents in prosocial organizational behavior: An examination of the intended beneficiaires of prosocial behavior. Journal of Applied Psychology, 79 (6), 836-844.

Meyer, J. P. (1997). Organizational commitment. In: C. L. Cooper \& I. T. Robertson (Eds.), International review of industrial and organizational psychology, 12, 175-228.

Mintzberg, H. (1983). Structure in five: Designing eeffective organizations. Englewood Cliffs, NJ: Prentice Hall.

Mintzberg, H. (1998). The structuring of organizations. In J. B. Quinn, H. Mintzberg \& R. M. James (Eds.), The strategy process: Concepts, contexts \& cases (pp. 276-311). Englewood Cliffs, NJ: Prentice Hall.

Moorman, R. H. (1991). Relationship between organizational justice and organizational citizenship behaviors: do faimess perceptions influence employee citizenship? Journal of Applied Psychology, 76, 845-855.

Morgan, M. L. (Ed.) (1992). Classics of moral and political theory. Indianopolis/Cambridge: Hackett.

Netemeyer, R. G., Boles, J. S., Mckee, D. O., \& McMurrian, R. (1997). An investigation into the antecedents of organizational citizenship behaviors in a personal selling context. Journal of Marketing, 61, 85-98.

Niehoff, B. P., \& Moorman, R. H. (1993). Justice as a mediator of the relationship between methods of monitoring and organizational citizenship behavior. Academy of Management Journal, 36 (3), 527-556.

Nunnally, J. C. (1978). Psychometric theory (2. ${ }^{a}$ ed.). Nova Iorque: McGraw-Hill.

Passos, A. M. (1999). Determinantes do comportamento de cidadania organizacional. Dissertação de mestrado em Psicologia Social e Organizacional, Lisboa: ISCTE.

Passos, A., \& Caetano, A. (2000). Comportamento de cidadania organizacional: Factores determinantes. Psychologica, 23, 71-93.

Rawls, J. (1971). A theory of justice. Cambridge, MA: Harvard University Press.

Rego, A. (1999a). Justiça organizacional: Entre a adolescência e a maturidade. In M. P. Cunha (Ed.), Teoria organizacional: Perspectivas e prospectivas (pp. 165-224). Lisboa: Publicações D. Quixote.

Rego, A. (2000a). Justiça e comportamentos de cidadania nas organizaçōes: Uma abordagem sem tabus. Lisboa: Edições Silabo.

Rego, A. (2000b). Justiça e comportamentos de cidadania. Comportamento Organizacional e Gestão, 6 (1), 73-94.

Rego, A. (2000c). Justiça organizacional: Desenvolvimento e validação de um instrumento de medida. Psicologia (aceite para publicação). 
Rego, A. (2000d). Comportamentos de cidadania organizacional: Uma abordagem empírica a alguns dos seus antecedentes e consequências. Tese de doutoramento não publicada. Lisboa: ISCTE.

Rego, A. (2000e). Percepçōes de justiça dos professores do ensino superior: Desenvolvimento e validação de um instrumento de medida. Proposto para publicação.

Rego, A. (2000f). Alguns dados seminais sobre as percepçōes de justiça dos professores do ensino superior. Psicologia, Educação e Cultura, IV (2), 361-374.

Rego, A., \& Sousa, L. (2000a). Comportamentos de cidadania docente universitária: A perspectiva dos estudantes. Psychologica, 25, 67-74.

Rego, A., \& Sousa, L. (2000b). Impactos dos comportamentos de cidadania docente sobre os alunos universitários: A perspectiva dos estudantes e dos professores. Linhas Críticas, 6 (10), 9-30.

Ross, W. D. (1959). The nicomachean ethics of Aristotle. Londres: Oxford University Press.

Scholl, R. W., Cooper, E. A., \& McKenna, J. F. (1987). Referent selection in determining equity perceptions: Differential effects on behavioral and attidudinal outcomes. Personnel Psychology, 40, 113-124.

Skarlicki, D. P., \& Folger, R. (1997). Retaliation in the workplace: The roles of distributive, procedural, and interactional justice. Journal of Applied Psychology, 82 (3), 434-443.

Skarlicki, D. P., \& Latham, G. P. (1996). Increasing citizenship behavior within a labor union: A test of organizational justice theory. Journal of Applied Psychology, 81 (2), 161-169.

Skarlicki, D. P.; Folger, R., \& Tesluk, P. (1999). Personality as a moderator in the relationship between fairness and retaliation. Academy of Management Journal, 42 (1), 100-108.

Sousa, F. H., \& Vala, J. (1999). Justiça nas organizaçōes: O modelo do valor do grupo e as orientações comportamentais face à mudança. Psicologia, XIII (1-2), 25-52.

Spencer, D. G. (1986). Employee Voice and Employee Retention. Academy of Management Journal, 29 (3), 488-502.

Sweeney, P. D., \& McFarlin, D. B. (1993). Workers' evaluations of the 'ends' and the 'means': An examination of four models of distributive and procedural justice. Organizational Behaoior and Human Decision Processes, 55, 23-40.

Sweeney, P. D., \& McFarlin, D. B. (1997). Process and outcome: Gender differences in the assessment of justice. Journal of Organizational Behavior, 18, 83-98.

Theotónio, S. A., \& Vala, J. (1999). A experiência de justiça e injustiça nas organizações: Um estudo qualitativo. Psicologia, XIII (1-2), 53-73.

Thibaut, J., \& Walker, J. (1975). Procedural Justice: A psychological analysis. Hillsdale, NJ: Erlbaum.

Thibaut, J., \& Walker, L. (1978). A theory of procedure. California Law Review, 66, 541-566.

Tsui, A. S., Pearce, J. L., Porter, L. W., \& Tripoli, A. M. (1997). Alternative approaches to the employee-organization relationship: Does investment in employees pay off? Academy of Management Journal, 40, 1089-1121.

Tyler, T. R., \& Bies, R. J. (1990). Beyond formal procedures: the interpersonal context of procedural justice. In J. S. Carroll (Ed.), Applied social psychology in business settings (pp. 77-98). Hillsdale, NJ: Erlbaum. 
Williams, S. (1999). The effects of distributive and procedural justice on performance. The Journal of Psychology, 133 (2), 183-193.

Justice perceptions of university teachers: a confirmatory study

(abstract) This article aims at showing how the construct of justice perceptions of university teachers is multi-dimensional. The sample comprises 206 teachers from 6 higher education institutions. The findings converge with those of Rego (2000e) and show that: a) teachers distinguish 5 justice dimensions: rewards distribution, work distribution, procedural, interpersonal and informational;

b) this five-factor model fits the data better than the alternative models containing 2, 3 or 4 factors; c) the measurement instrument shows good psychometric properties regarding parsimony, internal consistency and clarity of dimensional structure. 